\title{
Mononeuritis Multiplex Associated With Infectious Mononucleosis
}

\author{
J. A. LIVESON* and J. GOODGOLD**
}

SUMMARY: A patient with infectious mononucleosis was found to have a mononeuritis multiplex involving the long thoracic and contralateral suprascapular nerves. A review of all cases of asymmetrical brachial neuropathy associated with infectious mononucleosis revealed involvement only of the upper brachial plexus. The associated severe tonsillitis or pharyngitis (ipsilateral to the neuropathy in 2 cases) suggests a relationship to the neuropathy via the lymph drainage which is to the region of the upper brachial plexus.

RÉSUMÉ: Nous avons trouvé un patient atteint d'une mononucléose infectieuse en plus d'une mononévrite multiplex impliquant les nerfs long thoracique et suprascapulaire contralatéral. Une revue de tous les cas de neuropathie brachiale asymétrique associée avec une mononucléose infectieuse révèle uniquement une atteinte du plexus brachial supérieur. L'association d'une amygdalite sévère ou d'une pharyngite (ipsilatérale à la neuropathie dans 2 cas) suggère une relation avec la neuropathie via le drainage lymphatique, lequel est relié à la région du plexus brachial.

From the Electrodiagnostic Department, Institute of Rehabilitation Medicine, New York University Medical Center.

*Academic Career Trainee, Electrodiagnostic Department, Institute of Rehabilitation Medicine; present address: Department of Neurology, Albert Einstein College of Medicine, 1300 Morris Park Avenue, Bronx, N.Y., U.S.A.

**Professor, Department of Rehabilitation Medicine; Director, Electrodiagnostic Department, New York University School of Medicine.

This study was supported by grant No. 8-0162-814 from the John A. Hartford Foundation and supported in part under the designation of the New York University Center as a Rehabilitation, Research and Training Center, by the Social and Rehabilitation Service, Department of Health, Education and Welfare.

Reprint requests to Dr. J. A. Liveson, Neurology, Albert Einstein College of Medicine, 1300 Morris Park Ave., Bronx, N.Y. 10461, U.S.A.
The neurological complications of infectious mononucleosis include meningitis, encephalitis, myelopathy, cranial neuropathy, LandryGuillain-Barré syndrome, and asymmetrical brachial neuropathy. The brachial neuropathy is the rarest of these complications occurring at most once in even the largest published series. There are 13 reported cases in all, only 10 of these with motor deficits (Richardson, 1942; Saksena, 1943; Coogan, Martinson, Mathews, 1945; Wallerstein, Madison, 1950; Silfverskiold, 1951; Rugg-Gunn, 1954; Erwin, Weber, Manning, 1959; Gautier-Smith, 1965; Schnell, Dyck, Bowie, Klass, Taswell, 1966; Radin, 1967), 2 had sensory symptoms only (Hollister, Houck, Dunláp, 1956; Silverstein, Steinberg, Nathanson, 1972), and another was impossible to characterize since the only description is "brachial neuritis" (Wechsler, Rosenblum, Sills, 1946).

We present an 11th case of infectious mononucleosis with asymmetrical motor neuropathy, more specifically, with a mononeuritis multiplex. The mononeuritis multiplex pattern has been described with periarteritis nodosa, systemic lupus erythematosus, rheumatoid arthritis, sarcoidosis, amyloidosis, leprosv, and diabetes mellitus; it has not been documented with infectious mononucleosis. A review of the pre-. viously reported cases of asymmetrical motor neuropathy suggested a specific mechanism in patients with infectious mononucleosis.

\section{CASE REPORT}

The patient is a 19-year-old college student who complained of frontal headaches, photophobia, nausea, and chills. Physical exami- nation on admission to Indiana University Infirmary (May 19, 1971) was normal except for a temperature of $102.4^{\circ} \mathrm{F}$., injection of the sclera and pharynx, enlargement of the spleen and axillary nodes, and exudative tonsillitis which yielded betahemolytic (non-group A) streptococci on culture.

Nineteen months earlier, the patient had complained of fatigue, epigastric pain, and diarrhea. At that time a Paul-Bunnell test for infectious mononucleosis was negative, white cell count was 9,700 with $64 \%$ polymorphonuclear leukocytes, and $36 \%$ lymphocytes.

Laboratory: White cell count varied between 4,100 and 18,000. Differential count on May 21, 1971 was $50 \%$ polymorphonuclear leukocytes, $44 \%$ lymphocytes with $27 \%$ atypical cells, 1 monocyte, 3 eosinophiles, 1 basophile. Paul-Bunnell test for infectious mononucleosis was negative on May 21 and 22, weakly positive on May 24, and positive on May 26 and 27.

During his hospitalization, the patient developed a non-productive cough accompanied by râles over the right lung base; chest $\mathrm{x}$-rays were normal. Although bile was noted in patient's urine, liver function tests were normal except for a mild elevation of the alkaline phosphatase, and SGOT. The patient was treated with oral prednisone until transfer to Overlook Hospital (Summit, N.J.) 11 days later when the prednisone was gradually withdrawn and phenoxymethyl penicillin treatment started. In the next 5 days his lymphadenopathy and severe exudative tonsillitis cleared and he was discharged.

When he resumed his activities 1 
week later he noted weakness of his right arm. In retrospect, he could recall a vague ache in both shoulders 1-2 weeks earlier. His weakness progressed so that on neurological examination 3 months after the onset he had winging of the right scapula and weakness of the left infraspinatus muscle. Neurological evaluation was otherwise normal.

\section{ELECTRODIAGNOSTIC STUDIES}

Amplification was via a Grass P511R preamplifier feeding into a Tektronix 3A3 amplifier. Concentric electrodes were used for electromyographic examination. For motor conduction studies surface electrodes were used. Antidromic sensory nerve action potentials were evoked at the wrist and monitored by ring electrodes around the 2nd (median) and 5th (ulnar) digits. Supramaximal square pulse stimuli of 0.1-0.3 msec. duration were delivered at a rate of 1 per second from a Grass S-8 stimulator coupled to a General Radio isolation transformer.

Electrodiagnostic studies 3 months after the onset of symptoms revealed fibrillation potentials, positive sharp waves at rest, ànd normal motor unit potentials on volition in the right serratus anterior muscle. Similar findings were present at rest on examination of the left supraspinatus and infraspinatus muscles, but no motor unit potentials were present on volition. All other muscles tested were normal, including the following: bilateral deltoids, biceps, brachioradialis, rhomboids, flexor carpi radialis, first dorsal interosseous, upper trapexius; left serratus anterior, right supraspinatus, right infraspinatus. Bilateral antidromic median and ulnar sensory nerve action potential latencies and right median motor conduction velocity were normal.

Repeat examination 4 months later showed fibrillation potentials, positive sharp waves at rest, and normal motor unit potentials with complete interference patterns in the right serratus anterior, left supraspinatus and infraspinatus muscles. Other muscles tested were normal.

\section{DISCUSSION}

The marked neuropathic abnormalities on electromyography were restricted to the right serratus anterior, the left supraspinatus and left infrapinatus muscles, with complete sparing of all other muscles innervated through C5-6. This focal denervation was limited to muscles supplied by the right long thoracic and left suprascapular nerves. Involvement of several nerves remote from each other is, by definition, a mononeuritis multiplex pattern and has not been documented in any of the previously reported cases of infectious mononucleosis (although two patients may have had such involvement (Gautier-Smith, 1965; Schnell, et al., 1966) ).

We may draw certain conclusions based on the patterns of neuropathic involvement about differing pathogenetic mechanisms. A symmetrical polyradiculoneuropathy (Landry-Guillain-Barré syndrome) suggests a diffuse process such as seen in allergic experimental neuritis, and in some patients with diabetes mellitus or infectious mononucleosis. In contrast, a mononeuritis or a mononeuritis multiplex pattern suggests a focal process. In diabetes mellitus histological evidence of focal pathology has been documented in an autopsy study of a patient with mononeuritis multiplex (Raff, Sangalang, Asbury, 1968). The authors demonstrated infarcts associated with focal lesions of the vasa nervorum.

In all cases of asymmetrical motor neuropathy associated with infectious mononucleosis the lesions are clustered near the upper brachial plexus or $\mathrm{C}_{5-7}$ roots (with the possible involvement of $\mathrm{C}_{3-4}$ or the accessory nerve in one case (Schnell, et al., 1966) ). The clinical spectrum ranges from mononeuritis, mononeuritis multiplex, to radiculopathy. In addition to this localized plexus involvement, 10 of the 11 patients had pharyngitis or tonsillitis, often purulent. In addition to its frequent severity in these cases, what is even more curious is the restriction of the purulent pro- cess to the tonsil ipsilateral to the neuropathy in two cases (Silfverskiold, 1951; Rugg-Gunn, 1954). Since the tonsils drain to the deep cervical lymph nodes and these are contiguous to the upper brachial plexus, a possible focal connection is present. Adenopathy of the deep cervical nodes, either due to infectious mononucleosis or due to drainage from a superimposed tonsillitis, is a possible pathogenetic mechanism producing the asymmetrical motor neuropathies of infectious mononucleosis. Anatomical demonstration of this postulated mechanism will be difficult due to the extremely unlikely occurrence of fatalities in this most rare complication of infectious mononucleosis. Until such evidence is forthcoming, the clinician confronted with management of such a patient might consider a more aggressive early treatment of any suppurative tonsillitis with appropriate antibiotics in the hope of arresting or preventing a possible brachial neuropathy.

\section{REFERENCES}

COOGAN, T. J., MARTINSON, D. L., MATHEWS, W. H. (1945). Neurological symptoms of infectious mononucleosis. Illinois Medical Journal, 87, 296-302.

ERWIN, W., WEBER, R. W., MANNING, R. T. (1959). Complication of infectious mononucleosis. American Journal of Medical Science, 238, 699-712.

GAUTIER-SMITH, P. C. (1965). Neurological complications of glandular fever. Brain 88, 323-334.

HOLLISTER, L. E., HOUCK, G. H., DUNLAP, W. A. (1956). Infectious mononucleosis of the central nervous system. American Journal of Medicine, 20. 643-646.

RADIN, E. L. (1967). Peripheral neuritis as a complication of infectious mononucleosis Journal of Bone and Joint Surgery, 49A, 535-538.

RAFF, M. C., SANGALANG, V., ASHBURY, A. K. (1968). Ischemic mononeuroapthy multiplex in association with diabetes mellitus. Archives of Neurology, Chicago, 18, 487-499.

RICHARDSON, J. S. (1942). Serratus magnus palsy. Lancet, 1, 618-619.

RUGG-GUNN, M. A. (1954). Infectious mononucleosis: a review of the condition as seen in the Royal Navy. Proceedings of The Royal Society of Medicine, 47 , 759-774.

SAKSENA, H. C. (1943). Paralysis of the serratus anterior following glandular fever. British Medical Journal, 2, 267. 
SCHNELL, R. G., DYCK, P. J., BOWIE, F J. W., KLASS, D. W., TASWELL, H. F. (1966). Infectious mononucleosis: neurological and EEG findings. Medicine, Balt., 45, 51-63.

SILFVERSKIOLD, B. P. (1951). Akut "skulderneurit" vid mononucleosis infectiosa. Nord Med., 46, 1081.
SILVERSTEIN, A., STEINBERG, G., NATHANSON, M. (1972). Nervous system involvement in infections mononucleosis. Archives of Neurology, Chicago, 26, 353-358.

WALLERSTEIN, R. S., MADISON, L. (1950). Case report: infectious monunucleosis with hepatic dysfunction, throm- bocytopenic purpura, and isolated peripheral nerve palsy. American Practitioner, 1, 624-629.

WECHSLER, H. F., ROSENBLUM, A. H., SILLS, C. T. (1946). Infectious mononucleosis: report of an epidemic in any army post. Annals of Internal Medicine, 25, 113-133 and 236-265. 